\title{
A ATUAÇÃO DOCENTE NA MATERIALIZAÇÃO DO PROJETO POLÍTICO-PEDAGÓGICO EM UMA INSTITUIÇÃO PÚBLICA DE ATENDIMENTO À EDUCAÇÃO INFANTIL NO MUNICÍPIO DE ITAPORÃ-MS
}

\author{
Elis Regina dos Santos Viegas ${ }^{1}$, Andréia Vicência Vitor Alves ${ }^{2}$
}

\begin{abstract}
Resumo: Este trabalho tem como objetivo analisar a atuação dos docentes na construção e materialização do Projeto Político-Pedagógico, sendo este compreendido como instrumento de participação na gestão democrática das instituições de educação infantil. Para tanto foram realizados estudos bibliográficos e documentais; como também a pesquisa de campo junto aos professores que atuam na rede municipal pública de Itaporã-MS. Inicialmente conceituamos a partir do referencial teórico e do arcabouço normativo-legal brasileiro a concepção de gestão democrática e de Projeto Político-Pedagógico no âmbito educacional; depois caracterizamos o contexto institucional no qual o Projeto foi construído, bem como o tratamento dado a este instrumento e; por fim buscamos compreender de que forma os professores vivenciam a construção do Projeto e como este adquire ou não centralidade na prática docente.
\end{abstract}

Palavras-chave: Projeto Político-Pedagógico. Docente. Educação Infantil.

\section{THE ACTION TEACHERS IN MATERIALIZATION POLITICAL-PEDAGOGICAL PROJECT INSTITUTION IN A PUBLIC SERVICE TO CHILDHOOD EDUCATION IN MUNICIPALITY ITAPORÃ-MS}

Abstract: This study aims to analyze the action of teachers in the construction and materialization of the Political-Pedagogical Project, this being understood as a participation tool in the democratic management of childhood education institutions. For both studies were carried out bibliographic and documentary; as well as field research with teachers working in public municipal Itapora $-M S$. Initially we conceptualized from the theoretical framework and the Brazilian normative-legal framework the concept of democratic management and Political-Pedagogical Project in the education sector; then we

1 Doutoranda em Educação e Pós-graduanda na Especialização em Docência na Educação infantil (EDEI), ambos na Faculdade de Educação (FAED) da Universidade Federal da Grande Dourados (UFGD). Professora da rede municipal pública de Itaporã-MS.

2 Doutorada em Educação pela Universidade Federal de Mato Grosso do Sul (UFMS) e professora adjunta da Faculdade de Educação da FAED/UFGD. 
characterize the institutional context in which the Project was built, as well as the treatment of this instrument and; finally we try to understand how teachers experience the construction of the Project and how it acquires or not central in the teaching practice.

Keywords: Political-Pedagogical Project. Teacher. Childhood Education.

\section{INTRODUÇÃO}

Partimos do pressuposto de que a gestão democrática não acontece no vazio. Ela é fruto da interação coletiva dos que primam pelo caráter participativo da gestão ao promover o diálogo entre todos os envolvidos. Dentre os mecanismos que concorrem para a sua materialização figura o Projeto Político-Pedagógico (PPP) e a sua construção coletiva pelas instituições educacionais.

Todavia, discutir o PPP e seu processo de construção como mecanismo de efetivação da gestão democrática e, este processo tendo, entre outros sujeitos, o professor como protagonista, constitui-se em uma proposta relativamente nova para nós, pois, embora o assunto faça parte de nossas leituras ${ }^{3}$, nunca tivemos a oportunidade de problematizá-la no interior de uma instituição formal de ensino. Por isso, o interesse de aprofundamento da temática proposta, como forma de enriquecer o conhecimento da área, bem como apreender a centralidade do objeto pesquisado.

Nesse sentido, decorrente das preocupações acerca da construção do PPP no espaço da educação infantil, tem-se como questão norteadora: como o Centro de Educação Infantil Municipal de Itaporã-MS direciona a construção, elaboração e efetivação do Projeto Político-Pedagógico?

A partir desta questão, desdobram-se outras: o PPP é compreendido no interior da instituição investigada como mecanismo de promoção da gestão democrática? Ou, apenas se constitui em mais um instrumento burocrático de esvaziamento da educação pública? Qual o nível de participação e/ou envolvimento dos professores no processo de construção, (re) elaboração e utilização do PPP? De que forma o PPP serve como referência das ações encaminhadas no interior da instituição?

Nessa direção, apontamos como objetivo geral da pesquisa: analisar a atuação dos docentes na construção do Projeto Político-Pedagógico, sendo este compreendido como instrumento de participação na gestão democrática das instituições de educação infantil.

Alicerçado no objetivo geral, delineiam-se os seguintes objetivos específicos: analisar a concepção do PPP como mecanismo de materialização da gestão democrática no âmbito educacional a partir do arcabouço legal brasileiro, bem como da literatura da

3 Desde o curso de Pedagogia (2007-2010), Mestrado em Educação(2012-2014) e agora na Especialização em Docência na Educação Infantil - EDEI - (2014-2016). 
área; caracterizar o contexto institucional no qual o PPP foi construído, bem como o tratamento dado a este instrumento; e por fim, compreender de que forma os professores vivenciam a construção deste documento no espaço investigado e, como este adquire ou não centralidade na prática docente, levando em conta as especificidades da educação infantil.

Assim sendo, estruturamos este trabalho em seis partes, da forma que segue: primeiro, destacamos o mapeamento dos estudos que trazem a temática em tela, ainda apontamos os encaminhamentos metodológicos utilizados na pesquisa; segundo, tratamos dos desdobramentos da gestão democrática e seus condicionantes; terceiro, indicamos conforme referencial teórico o PPP como mecanismo de constituição do espaço da gestão democrática; quarto, caracterizamos o PPP do lócus da pesquisa; na quinta parte, analisamos a participação docente na construção e efetivação do PPP, buscando compreender as percepções de consentimento e/ou consciência coletiva; e por fim, na sexta e última, inferimos as considerações finais.

\section{Encaminhamentos metodológicos: o tema em destaque}

Para melhor compreender a importância e a diversidade do tema investigado recorremos aos resumos disponíveis no banco de dados da Biblioteca Digital Brasileira de Teses e Dissertações (BDTD) ${ }^{4}$ no período de 1988 a 2014. Identificamos um total de 925 trabalhos (683 dissertações e 242 teses) que abordaram o tema PPP dentro das etapas (educação infantil, ensino fundamental, ensino médio), modalidades (educação de jovens e adultos, educação profissional e do campo) e níveis da educação brasileira (básica e superior).

A partir desse levantamento elaboramos uma síntese dos dados encontrados, que indica o crescente interesse pelo tema geral "Projeto Político-Pedagógico" nos 2000, pois no período de 1988 a 1999 o referido tema representava apenas 2,2\%; já nos anos 2000, o percentual aumenta para 51,2\%, registrando 473 trabalhos. No entanto, o maior crescimento observado foi no período de 2011 a 2014, uma vez que 43,4\% (em 5 anos) do total de trabalhos identificados (401 pesquisas) nesse período se dedicam a temática.

Destacamos desse levantamento o grupo temático denominado "Projeto PolíticoPedagógico e Educação Infantil", que contou com 9 trabalhos (7 dissertações e 2 teses), dos quais alistamos no subgrupo "Projeto Político-Pedagógico, Gestão Democrática e Educação Infantil", que totalizou 2 dissertações (2005 e 2007), sendo as duas desenvolvidas em centros de educação infantil na região Sudeste.

4 Disponível em: <https://www.google.com.br/\#q=biblioteca+nacional+disserta\%C3\%A7\%C3\%B5es+e tteses>. Acesso em: nov. de 2015. 
No que diz respeito as duas dissertações identificadas, ressaltamos primeiro a pesquisa de Celante (2005), que analisa planejamentos institucionais e sua relação com os PPPs de duas creches da rede pública de Jundiaí-SP; o segundo estudo é o de Evangelista (2007), que é resultado da pesquisa realizada em uma Escola Municipal de Educação Infantil de Bauru-SP, cujo objetivo foi identificar no plano teórico e prático os elementos que constituem o PPP.

O mapeamento revela que estudos relacionados a construção do PPP, tendo como lócus de pesquisa instituições de educação infantil, não foram objeto de interesse no período (1988 a 2014), o que indica a necessidade do incremento de estudos sobre os desdobramentos do PPP como canal legítimo de incentivo da gestão democrática nesses espaços.

No que diz respeito ao desenvolvimento da presente pesquisa optamos por uma abordagem qualitativa, que segundo Esteban (2010) admite considerar o contexto e as experiências dos atores envolvidos e, para o suporte desta, utiliza-se a análise documental nacional e municipal, como: Constituição Federal (CF/1988); Lei de Diretrizes e Bases da Educação Nacional (LDB) Lei no 9.394/1996; Diretrizes Nacionais para a Educação Infantil (DCNEIs); PPP da instituição investigada, entre outros. Além do quadro teórico que trata da gestão democrática e do PPP no campo educacional público, como: Paro (2008), Bastos (2005), Gracindo (2007), Veiga (2002, 2007, 2012) e outros.

Para a coleta de dados, empregamos questionários com questões fechadas, buscando obter elementos precisos sobre a percepção dos professores que atuam na instituição pesquisada, para isso aplicamos por meio deste instrumento questões abertas e fechadas a 03 professoras que atuam no lócus investigado. $\mathrm{O}$ tratamento e a interpretação dos dados levantados deram-se pelo procedimento de análise de conteúdo (FRANCO, 2008).

Delimitamos como recorte temporal da pesquisa o ano de 2014, o qual se justifica em função da (re) elaboração do PPP que ocorreu na instituição lócus da pesquisa neste ano, conforme informado no próprio documento.

\section{Desdobramentos da gestão democrática e seus condicionantes}

Tratar da oferta e da promoção do ensino público - dentro de uma perspectiva democrática - na educação infantil, obrigatoriamente nos remete ao todo organizacional da educação, desde a formulação da agenda das políticas até sua concretização no espaço educacional. Perpassa aí a questão da gestão democrática como elemento para promover a participação de todos os envolvidos.

A Constituição Federal Brasileira (CF/1988) estabelece, em seu artigo 206, princípios para a educação nacional, dentre eles: obrigatoriedade, gratuidade, liberdade, igualdade e gestão democrática. Enquanto a Lei de Diretrizes e Bases da Educação 
Nacional (LDB) Lei no 9.394/1996, art.14, inciso I e II, estabelece que "Os sistemas de ensino definirão as normas da gestão democrática do ensino público na educação básica, de acordo com as suas peculiaridades e conforme os seguintes princípios", sendo estes: "I - participação dos profissionais da educação na elaboração do projeto pedagógico da escola; II - participação das comunidades escolar e local em conselhos escolares ou equivalentes" (BRASIL, 1996).

Respaldada nesses princípios a democratização da gestão surge como um norte nos processos decisórios nos sistemas de ensino e, em particular, nas unidades escolares. A gestão democrática aparece então, como uma proposta de ação a ser efetivada, tendo em vista a garantia dos processos participativos.

Alves $(2014$, p.21) assinala que a gestão democrática é “[...] um processo de caráter político-pedagógico e administrativo no qual se dá a participação efetiva da sociedade em todos os níveis de decisão e execução da atividade educativa, com real poder de interferência e manifestação". Em outras palavras, o ato de administrar aparece associado a dimensão política, mas sem deixar a pedagógica, isto é, têm uma relação indissociável.

Bastos (2005) e Paro (2008) informam que a gestão democrática no espaço educacional advém de uma percepção administrativa que envolve a participação ativa dos gestores, professores, funcionários e da comunidade. Paro (2008) explica que este tipo de gestão contém na sua essência o exercício participativo nas decisões, ao buscar instrumentos que viabilizem a descentralização destas de modo democrático, tendo em vista o alcance de objetivos educacionais estabelecidos coletivamente.

Todavia, Bastos (2005, p.11) analisa que o entendimento da gestão democrática não surge espontaneamente, este é "[...] construído por sujeitos históricos conscientes dos direitos negados e das contradições que se manifestam numa determinada conjuntura política e econômica". O autor considera ser fundamental democratizar os debates no âmbito escolar, de tal forma que os envolvidos possam se apresentar como sujeitos ativos dentro do espaço público de educação.

Nesse contexto, não há como deixar de mencionar o necessário repensar da estrutura organizacional e da gestão de instituições de atendimento à primeira infância. Tendo em vista as especificidades dessa etapa, já que no Brasil, a educação infantil passou a ser responsabilidade do Estado apenas a partir da CF/1988 e a integrar o sistema nacional de educação a partir da LDB/1996, abrangendo, atualmente, creches e pré-escolas que compõem esta etapa responsável pela educação e o cuidado das crianças de 0 a 5 anos de idade.

O reconhecimento do direito à educação das crianças pequenas em espaços públicos é um processo bastante recente cujos resultados ainda estão aquém das reais necessidades da infância brasileira (SILVA; OLIVEIRA; NOGUEIRA, 2012), tendo em conta que até poucas décadas, o acolhimento de crianças era viabilizado por intermédio de órgãos da assistência social, isto é, o atendimento não tinha um propósito 
relacional entre o cuidar e o educar de modo formal. As autoras apontam a necessidade de aprofundamento de estudos sobre o cotidiano dessas instituições para que possamos pensar em ações de atendimento a esta etapa.

Nesse sentido, compreendemos que, os estabelecimentos de educação infantil, enquanto instituições educativas tiveram e, ainda têm sua estrutura e funcionamento influenciados por percepções de cunho assistencialista (direito da mãe trabalhadora), mesmo após CF/1998 estabelecer esta etapa (creche e pré-escola) como espaço educacional (direito da criança). Isso também ocorre pela falta de referência, tendo em vista sua recente inserção no sistema de ensino (LDB/1996), em outras palavras, instituições de educação infantil têm como norte administrativo os sistemas escolares existentes (ensino fundamental), ou seja, os modelos de gestão já instalados.

Sobre a falta de referência na gestão, Bastos (2005) analisa que esta pode ser resultado da indefinição normativa-legal - CF/1988 e LDB/1996 -, por não indicar com clareza o princípio da gestão democrática, o que acaba por fortalecer um tipo de gestão que se preocupa muito mais com a operacionalização das ações burocráticas e financeiras, do que com as discussões coletivas para tomada de decisão no âmbito da gestão. Tendo em conta que, da forma como está determinada, deixa muito a critério das instituições e seus gestores o modo como este processo será direcionado.

Mesmo diante dessa inconsistência, Gracindo (2007, p.35) indica a gestão democrática como "objetivo" e como um "percurso". A autora considera ser "um objetivo porque trata-se de uma meta a ser sempre aprimorada"; mas, também, "é um percurso, porque se revela como um processo que, a cada dia, se avalia e se reorganiza”. Com essa compreensão, o movimento pela democratização da gestão, fundamentalmente, distingue-se por quatro elementos: "participação, pluralismo, autonomia e transparência”.

Embora a autora reconheça que nem sempre a realidade educacional viabilize, de fato, a assunção da participação, por conta da conveniência das decisões que são acertadas antecipadamente e, por consequência, os objetivos da "participação" que são igualmente restringidos, abandona-se assim, "O sentido público de um projeto que pertence a todos; [...] o sentido coletivo da sua construção" (GRACINDO, 2007, p. 36).

No que diz respeito ao "pluralismo", a autora esclarece que este se concretiza por meio de atitudes de reconhecimento e respeito às diferentes identidades, posicionamentos, opiniões, ideias, sendo estas, permeadas por momentos de debate, diálogo e conflito.

Já em relação à "autonomia”, ressalta-se de acordo com Barroso (1998), que ela “[...] está etimologicamente ligado à ideia de autogoverno, isto é, à faculdade que os indivíduos (ou as organizações) têm de se regerem por regras próprias" (apud GRACINDO, 2007, p.37, grifo da autora). Assim, a autonomia é tomada a partir da democratização interna e externa da unidade, "politizando-a" e possibilitando o seu 
desenvolvimento, tanto na instituição, quanto nos próprios "sujeitos" que fazem parte da realidade educacional.

Destaca-se ainda, como imprescindível, a prática da "transparência", por estar atrelada a percepção de "escola como espaço público". Elemento que garante a visualização da instituição educativa, dentro de um cenário público normativo-legal regido por decisões administrativas, também de ordem econômica, o que demanda posicionamento ético. A "transparência afirma a dimensão política da escola" (GRACINDO, 2007, p. 38).

Diante disso, projetos educativos construídos democraticamente e com intenções amplas são permeados por aspectos valorativos, por se constituírem como "processo que se vive como coletivo" e, portanto, "valorizado e colocado ao alcance do grupo" (VEIGA; ARAUJO, 2012, p. 30). Esse movimento permite a composição de novas relações entre gestores, professores, alunos, funcionários e pais.

\footnotetext{
Ocorre que todos esses elementos e alicerces da gestão democrática necessitam de uma base concreta para sua viabilização: os espaços de encontro, discussão e trocas. A partir desses espaços de prática democrática são deliberados e construídos os caminhos que a escola deve percorrer. E o retrato dessa caminhada será revelado no Projeto Político-pedagógico da escola (GRACINDO, 2007, p.37-38, grifo nosso).
}

Portanto, apresenta-se o PPP como mecanismo democrático, que potencializa o ambiente de constituição e emancipação da instituição, como também do docente que nela convive e, portanto, canal legítimo de melhoria da atuação no espaço público educacional. Embora, conforme adverte Spósito (2005), não há canal institucional que venha ser criado no sistema público de ensino que, por si só, transforme o espaço educativo, se não estiver estabelecida, de fato, a possibilidade de valorização da participação, enquanto vontade coletiva, direcionada pela busca de transformar a existência concreta.

\section{O PPP como mecanismo de constituição da gestão democrática}

A assunção do Projeto Político-Pedagógico (PPP), como instrumento de organização do trabalho da escola como um todo está fundamentada nos princípios de: a) igualdade: condições para acesso e permanência, o que requer ampliação do atendimento com simultânea manutenção de qualidade; b) qualidade para todos: perfil de sociedade e de cidadão que se pretende formar, assim como as ações específicas para obtenção desses fins; c) gestão democrática: implica o repensar da estrutura de poder da escola, o que inclui, necessariamente, a ampla participação dos representantes dos diferentes segmentos nas decisões/ações administrativo-pedagógicas; d) liberdade: condição para aprender, ensinar, pesquisar e divulgar o saber direcionado para uma intencionalidade definida coletivamente; e) valorização profissional: formação (inicial 
e continuada), condições de trabalho e remuneração, elementos esses indispensáveis ao exercício da profissão (VEIGA, 2002).

Veiga assinala que o reconhecimento desses princípios “[...] está em garantir sua operacionalização nas estruturas escolares, pois uma coisa é estar no papel, na legislação, na proposta, no currículo, e outra é estar ocorrendo na dinâmica interna da escola, no real" (VEIGA, 2002, p. 22). Assim, o processo de construção do PPP se orientará no que se "quer fazer" e "porque fazê-lo" (VEIGA, 2007, p. 56), pois, desse modo, não se constituirá na simples reprodução burocrática, mas na consolidação de um processo reflexivo que exige a mobilização e o anseio político-social do coletivo.

No âmbito escolar, o PPP “[...] deve orientar-se para capacidade de olhar as práticas e suas consequências e pela redução dos mecanismos de regulação convergentes que sempre dominaram a escola" (VEIGA, 2007, p. 58). Nessa posição, Libâneo, Oliveira e Toschi (2012) analisam que o PPP reflete as intenções, os objetivos, as aspirações e os ideais da equipe escolar, tendo em vista um processo educacional que busque atender todos os educandos.

Para estes autores existem quatro razões que justificam a importância desse projeto: a) é unidade de ação que se baseia em valores, convicções e práticas participativas; b) é resultado de trabalho coletivo com vistas a objetivos comuns - políticos, sociais e pedagógicos -; c) é prática educativa, investigativa e reflexiva, por manifestar o caráter formativo do ambiente de trabalho; d) é expressão do grau de autonomia da equipe escolar, por se respaldar no trabalho coletivo, o que motiva a construção de pontos de partida (princípios) e de chegada (objetivos) comuns.

Nessa condição, tal projeto, de acordo com Veiga (2012) pode ser referência para a construção contínua de inovação democrática, para a organização da prática pedagógica, para o esclarecimento das intencionalidades educacionais e para a articulação solidária das participações dos diferentes protagonistas.

Isso significa reafirmar a necessidade do exercício constante da participação coletiva em todas as dimensões administrativa, financeira, pedagógica e dialógica, mediante: a) a reflexão sobre as funções da escola, por meio da problematização da relação complexa entre sociedade e escola; b) o rompimento com a atual organização de trabalho no interior da escola; c) a criação e consolidação de novos mecanismos de democratização; d) a definição de critérios e instrumentos de avaliação do PPP (VEIGA, 2007).

Com esse intuito, Libâneo, Oliveira e Toschi (2012) sugerem que as decisões a serem tomadas em razão do PPP devem considerar, minimamente, os seguintes pontos: a) princípios: consenso em torno de opções sociais, políticas e pedagógicas, do papel social e cultural da escola; b) objetivos: intenções concretas, com base em um diagnóstico prévio; c) sistema e práticas de gestão: a participação na gestão democrática implica decisões sobre as formas de organização e de administração; d) unidade teóricometodológica: concepção de currículo e linha pedagógico-didática; e) sistema explícito e transparente de acompanhamento e avaliação do projeto e das atividades da escola: 
esse componente coloca em evidência as dificuldades surgidas na implantação e na execução do projeto, confrontando o que foi decidido e o que está sendo feito.

Portanto, existe a compreensão de que o PPP vai além de um simples agrupamento de planos de ensino e de atividades diversas (VEIGA, 2012). Almeja-se um projeto construído e vivenciado em todos os momentos, por todos os envolvidos como processo educativo. Constitui-se assim, em uma ação intencional, com um sentido explícito, com um compromisso definido conjuntamente por sujeitos conscientes.

\section{Caracterização do PPP no lócus da pesquisa}

Encaminhamentos de gestão, no âmbito da educação infantil, relativos à elaboração do PPP podem sinalizar sobre a importância real atribuída a participação democrática, revelando um contexto de posicionamento coletivo ou de consentimento das ações.

Nessa direção, o lócus ${ }^{5}$ da pesquisa é o município de Itaporã-MS, especificamente, o Centro de Educação Infantil Municipal $(\mathrm{CMEI})^{6}$, que até o momento é a única unidade educacional que presta atendimento à educação infantil correspondente a creche ( 0 a 3 anos) no município.

Essa instituição caracteriza-se como uma unidade educacional pública que atende as classes populares, em consonância com art.154 da Lei Orgânica do Município de Itaporã (LOM - 1990). A instituição atende, atualmente, 7 turmas, divididas entre berçário, maternal e jardim, com uma média de 25 crianças e 3 profissionais (professora, monitora e auxiliar) em cada turma.

O município, até o momento, não possui um Conselho Municipal de Educação. Assim, a regulamentação e a organização da rede municipal pública ficam a cargo do Conselho Estadual de Educação de MS, o que se configura como um impeditivo no estabelecimento de discussões e reivindicações acerca da educação pública municipal.

No que diz respeito ao PPP do CMEI, objeto da pesquisa, este é concebido, segundo seu próprio documento, como plano orientador das ações da instituição e define os objetivos almejados para o desenvolvimento e aprendizagem das crianças baseados no Referencial Curricular do município (ITAPORÃ, 2014).

Tal projeto foi reelaborado no ano de 2014 , a partir da reflexão da comunidade escolar (direção, coordenação e professores), com base em diagnóstico e anseios frente

5 Possui uma área de $1.321 .811 \mathrm{~km} 2$, composto por 5 distritos. Com uma estimativa em 2014 de 22.568 habitantes, aproximadamente $1 \%$ da população total do estado. Disponível em: <http://www. cidades.ibge .gov.br/xtras/perfil.php?lang=\&codmun=500450\&search=||infogr\%E1ficos:informa\%E7\%F5es-completas >. Acesso em: fev. de 2015.

6 Criado em 1994 como a primeira instituição do município a atender a faixa etária a partir de 0 ano de idade. 
aos desafios educacionais presentes na instituição de educação infantil. O documento está dividido em três capítulos: marco situacional, marco teórico e marco operacional (ITAPORÃ, 2014).

O primeiro capítulo - Marco Situacional - apresenta a instituição, o histórico da educação infantil e do próprio CMEI, além dos aspectos legais de âmbito nacional CF/1988, Estatuto da Criança e do Adolescente (ECA) Lei no 8.069/1990, LDB/1996 e Referencial Curricular Nacional para a Educação Infantil (RCNEI) - e municipal/ institucional - Decreto no 111/1994, Lei no 1.541/1996, Deliberação CEE/MS no 7.228/2003; o contexto socioeconômico e cultural do estado de MS e do município; a caracterização da comunidade atendida no ano de 2014; estrutura física e material; organização das turmas e recursos humanos; a formação inicial e continuada dos profissionais que atuam na instituição; a composição da Associação de Pais e Mestres (APM) e os desafios para o ano de 2015 nos aspectos pedagógicos e administrativos.

No segundo capítulo - Marco Teórico - são abordados os temas: visão de mundo e características da atualidade; o papel da educação infantil frente à nova conjuntura; os referenciais de qualidade da educação infantil e a articulação entre o cuidar e o educar; as finalidades da educação infantil; e a missão e os valores da instituição.

No terceiro e último capítulo - Marco Operacional - se apresenta os fins e objetivos do CMEI; a organização e o referencial curricular; estruturação do trabalho cotidiano, que trata do ambiente, salas de atividades e rotina; a avaliação na educação infantil e da aprendizagem; trata ainda da gestão democrática na instituição; e por fim, do acompanhamento e avaliação do projeto.

O PPP da instituição investigada assinala como "Marco Situacional" o "[...] movimento interno da escola, conhecer seus conflitos e contradições, fazer diagnóstico e definir onde é prioritário agir" (ITAPORÃ, 2014, p.07). Nesse sentido, a proposta firmada é determinar quais prioridades devem ser trabalhadas no ambiente institucional.

Ainda nesse capítulo, no item 1.9, traz a "Gestão Democrática", sendo esta compreendida no documento como uma ação de composição da APM, na qual indica nomes e funções de cada membro. A expressão "Gestão Democrática", também é citada no item 3.5 do terceiro capítulo, que aponta as funções da APM como um todo. No entanto, não aparece no texto documental nenhuma menção sobre o entendimento da instituição em relação ao conceito/concepção da gestão democrática da educação, o termo é citado, mas não há discussão ou conceituação.

O CMEI não conta com Conselho Escolar, somente foi percebido a APM, que não possui uma atuação ativa dentro da instituição, pelo contrário, esta foi organizada de forma a atender as questões administrativas e burocráticas de recebimentos de recursos materiais e financeiros. O calendário escolar da instituição é determinado pela Gerência de Educação do município (GEDU), em relação a organização da rotina institucional, esta é estabelecida pela diretora e pela secretária escolar, ambos os casos, 
calendário e rotina, não contam a participação dos demais profissionais do CMEI na sua construção.

O PPP, de acordo com o documento, aponta como desafios (item 1.10), os aspectos pedagógicos e administrativos: apresenta-se como desafio pedagógico a exposição do projeto para a comunidade escolar, a revisão periódica do documento, exposição semanal das atividades desenvolvidas por cada turma e a realização de estudos teóricos e práticos; outro desafio apontado diz respeito ao aspecto administrativo, que assinala como imperativo adquirir brinquedos e buscar parceiros para a oferta de formação continuada aos professores.

Em relação ao "Marco Operacional”, o PPP do CMEI traz como objetivos: formar indivíduos (educandos) críticos coerentes, criativos, solidários e ativos, construtores de conhecimento (individual e social), nas quais as bases psicológicas são as do construtivismo; assegurar os direitos da criança, preservando suas características etárias e atendendo suas necessidades básicas; considerar as dimensões do cuidar e do educar, em sua inseparabilidade; respeitar a diversidade de expressões culturais, sem qualquer tipo de discriminação; e por fim, garantir às crianças do CMEI atendimento qualitativamente satisfatório, visando seu desenvolvimento integral (ITAPORÃ, 2014).

Podemos inferir com base na leitura do PPP do CMEI, que o mesmo apresenta fragilidades no sentido da compreensão do conceito de gestão democrática, pois embora apresente o termo, este apenas aparece para designar a composição e as funções da APM. Além disso, a ação de promover a gestão democrática não é citada como desafio, ou seja, não existe ou não é percebida como um problema. Embora, possamos considerar que mesmo em segundo plano, os encaminhados dados ao PPP apresentam nuances democráticas, em que percebemos a iniciativa de "apresentação do documento a comunidade escolar", mesmo não tendo sido envolvidos em sua construção; a busca pela formação de indivíduos (educandos) críticos coerentes, criativos, solidários e ativos, construtores de conhecimento (individual e social).

Embora, possamos identificar a proposta de "rever periodicamente o PPP com a diretora, coordenadora, professores", apesar de excluir os outros funcionários (serventes, merendeiras, auxiliares de sala, monitoras, vigias, pais e alunos). $\mathrm{O}$ documento ressalta a necessidade da realização de estudos teóricos e práticos, mas não para revisão do PPP, embora o próprio documento cite como desafio "a revisão periódica" deste.

Ressaltamos ainda, que o PPP dessa instituição não cita ou considera as Diretrizes Curriculares Nacionais para Educação Infantil (DCNEIs), aprovada em 2009, que se constitui como documento mandatório, em que reúne os princípios fundamentados e procedimentos definidos pela Câmara de Educação Básica do Conselho Nacional de Educação, para elaboração de ações, planejamento, execução e avaliação de propostas pedagógicas e curriculares da educação infantil (BRASIL, 2010).

Diante desse contexto, recorremos a Ganzelli (2005) que analisa a mobilização no sentido da transformação organizacional escolar. Para o autor esta transformação ou 
reorganização não pode ser apreciada como algo que se insere, mas como um processo concebido no âmbito da realidade educacional. E, ainda, considera que a construção do espaço democrático exige a mudança drástica do trabalho educacional e das relações nele estabelecidas. Portanto, faz-se necessário o planejamento coletivo dessas mediações, dentro de uma perspectiva democrática de discussão.

\section{A participação docente na construção e efetivação do PPP: entre o consentimento e a consciência coletiva}

Nessa parte do estudo, buscamos compreender de que forma os professores vivenciam a construção do Projeto Político-Pedagógico (PPP) no espaço investigado e, como este adquire ou não centralidade na prática docente a partir das questões levantadas.

Todavia, inicialmente, buscamos caracterizar (formação, função, tempo de profissão) quem são os sujeitos participantes da pesquisa, como forma de compreender suas considerações sobre o objeto investigado.

Os questionários foram respondidos por três professoras, que apresentam as seguintes características: as 3 professoras possuem ensino superior (Pedagogia); destas 2 professoras obtiveram o título em instituições privadas de modalidade a distância, nos anos de 2007 e 2010 e, 1 professora em uma instituição estatal, de modo presencial, no ano de 2002. Do ponto de vista da formação inicial, podemos inferir que todas possuem formação adequada para atuação na etapa da educação infantil.

Ainda, buscamos saber se estas professoras possuem formação complementar, como por exemplo, pós-graduação (lato sensu e/ou strictu sensu). Nessa direção, identificamos entre as docentes os seguintes aspectos: no item (questionário) de pós-graduação, todas apresentam titulação em nível de lato sensu. Tais especializações são distribuídas da seguinte forma: 3 professoras possuem em Educação Especial e 1 professora apresenta mais uma especialização em Educação Infantil, todas estas formações foram cursadas em Instituições Ensino Superior (IES) privadas, na modalidade a distância. Essas informações indicam uma desvinculação da especialização com a área em que atuam, tendo em vista que a especialização na área não é critério de ingresso na carreira.

No que se refere ao vínculo empregatício, ingresso na carreira e tempo de atuação: 2 professoras são concursadas, sendo que estas ingressaram na carreira na primeira metade dos anos 2000 e, 1 professora é contratada, atuando na área depois de 2010. Quanto ao exercício da função de professora na área da educação infantil, todas apresentam experiência nessa etapa -2 têm mais de 5 anos de experiência e 1 professora menos de 2 anos.

Dito isso, buscamos saber das professoras a compreensão delas sobre o PPP como projeto identitário do espaço da educação infantil, "uma intervenção no presente visando o futuro" (VEIGA; ARAUJO, 2012, p.31). Para a Professora 1 "é um documento que 
deveria ser elaborado com a participação de todos os envolvidos, tanto pais, alunos, equipe escolar e a comunidade em geral, por nortear todos os caminhos que a instituição irá trilhar"; outra Professora (2) apontou que o PPP "é uma referência norteadora em todos os âmbitos da ação educativa da escola, sendo necessária a participação de todos os componentes da comunidade escolar, para que seja a expressão viva de um projeto coletivo"; e a Professora 3 disse que o PPP "é um documento que traz o referencial curricular do município".

A fala das duas primeiras professoras está consoante com as DCNEIs (2009) e com a concepção de gestão democrática da educação supramencionada, que recomenda o PPP como plano orientador das ações da instituição, sendo definidor das metas pretendidas para a aprendizagem e o desenvolvimento das crianças. Para que ele seja efetivado, sua elaboração deve ocorrer por meio do processo coletivo, envolvendo a participação da direção, dos professores e da comunidade escolar (BRASIL, 2010). Já a Professora 3 entende o PPP, mais no sentido de reprodutor de outro documento existente, ou seja, de divulgação do Referencial Curricular do município.

No posicionamento das três professoras, podemos perceber que conceitualmente o PPP traz um sentido de ação na prática cotidiana. Sobre isso, Veiga (2007) coloca que é ainda imperativo afirmar que a construção do projeto pedagógico exige uma reflexão acerca da concepção, das finalidades da educação e sua relação com a sociedade "É uma exigência necessária, em que a qualidade e o sentido do que se faz valem mais" (Ibid., p.20).

Destacamos, conforme informado nos questionários, que não houve nenhum momento formativo de preparação ou de esclarecimento para a discussão da (re) elaboração do PPP. Contudo, o fato das professoras terem como formação inicial o curso de Pedagogia, já indica de imediato que estas têm alguma compreensão do processo (concepções e princípios). Embora, consideramos ser necessários, diante do contexto atual, momentos de reflexão antecedentes a construção de ações estratégicas, principalmente, no caso da educação infantil que na sua constituição histórica possui pontos a serem debatidos: educação integral e/ou parcial, indissociabilidade entre o cuidar e o educar, formação adequada, profissionalização, avaliação da aprendizagem, desenvolvimento infantil, direito a educação, entre outros.

A partir do entendimento de cada professora quanto ao PPP, buscamos compreender como se deu a participação e/ou envolvimento destas no processo de (re) elaboração desse projeto. A Professora 1 explicou "minha participação foi maior no realinhamento da proposta curricular"; a Professora 2 explanou: "reelaboramos o marco situacional, organização das turmas por níveis, caracterização, estrutura física e material, composição da APM e do corpo docente, referencial curricular"; a Professora 3 disse que "os professores contratados não participaram da discussão, somente os concursados. Fomos chamadas apenas no momento da apresentação".

A Professora 1 envolveu-se com a parte da organização do referencial curricular no que concerne aos conteúdos e habilidades dispostos no documento. A Professora 2 
apresentou um maior grau de participação na elaboração do projeto, porém os elementos levantados por ela indicam, conforme verificado junto ao PPP, uma relação técnica no que diz respeito a preenchimentos de dados - quantidades e características de cada turma, recursos materiais, membros da APM e do corpo docente -, embora possamos perceber seu envolvimento também nas discussões referentes à proposta curricular.

Para compreender como aconteceu esta discussão para suprir as lacunas do PPP anterior (2013), procuramos saber quais foram os espaços, momentos, períodos designados para a (re) elaboração do documento. A Professora 1 informou "os professores foram divididos', cada grupo realinhou uma turma, discutimos e incluímos no PPP"; a Professora 2 acrescentou que as discussões aconteceram "no período noturno e em parte do recesso de fim de ano". Tal explicação justifica em parte a ausência de professores contratados na elaboração do PPP, pois, é sabido que professores contratos, geralmente encerram suas atividades remuneradas junto com o final do ano letivo, o que se constitui como um impeditivo no envolvimento de todos os docentes na construção do projeto, porém estes poderiam ter participado nos momentos dos períodos noturnos informados pela Professora 2.

De acordo com o Parecer CNE/CEB no 20/2009 (BRASIL, 2010), o PPP deve delinear suas ações de construção, elaboração, organização e execução da instituição de educação infantil fundamentadas em determinações políticas, culturais e científicas coletivamente formuladas. Nesse sentido, o projeto do CMEI não cumpre integralmente as determinações deste Parecer, pois não envolve todos os profissionais que atuam na instituição, principalmente, no que diz respeito aos professores contratados. Uma possível justificativa dessa falta de engajamento destes professores seja talvez, por conta da intensa rotativa docente, pois não há garantia legal desses profissionais atuarem no ano subsequente na mesma unidade.

Do ponto de vista das professoras que participaram da elaboração do PPP, verificamos quais seriam na percepção delas os pontos debatidos mais relevantes. A Professora 1 destacou a "opinião de cada professor, relatando o que deu certo e o que não funcionou em cada turma"; a Professora 2 reforçou ao afirmar "a troca de ideias". As duas professoras indicaram como relevante o momento de troca de informações em relação a parte pedagógica, atividades, projetos, experiências em específico.

Para Resende (2005), a postura reflexiva é inerente ao ato educativo crítico e pressupõe momentos de contemplação investigativa das práticas já desenvolvidas, por se constituir em elementos positivos, individuais e coletivos, voltados para a construção da realidade educativa.

Tendo em vista, que as professoras consideraram como relevante os momentos de "troca de experiências", procuramos entender como estas se posicionam sobre a ausência participativa dos outros profissionais nos momentos de diálogo do projeto. As professoras demonstraram opiniões diversas a respeito da ausência de outros membros da equipe. Para a Professora 1 todos deveriam participar da discussão, como forma de "ampliar o diálogo, observar outros pontos de vista". Já a Professora 2, apontou que 
não deve haver envolvimento de todos nesses momentos, pois "nem todos estão abertos para a realização da atividade, alguns se mostram alheios e apáticos quanto ao tema discutido". A Professora 3, entende que esta participação é extremamente limitada "já que os contratados não participam, só os concursados”, no entanto, compreendemos que o envolvimento e ponto de vista do professor contratado também poderia contribuir com diálogo.

Conforme Resende (2005 p. 239), a constituição dos profissionais da educação é marcada por situações que poderíamos considerar, no mínimo, "[...] como ricas em ambiguidades, diversificadas em suas vivências e traduzidas por interpretações que envolvem óticas, éticas, e representações particulares". Mas, ao mesmo tempo, de acordo com a autora, em que possuem a dimensão particular também são coletivas e, em decorrência, capazes de produzir um tipo próprio de relação que culmina em processos convergentes, contraditórios, solidários ou não.

O referido autor considera que tal ambiguidade pode ter como consequência, o posicionamento de profissionais que pensam e agem como se estivessem sendo regidos por ações autônomas e sem repercussão para o espaço compartilhado. "Nesse caso há um falseamento da complexidade do cenário docente que, por natureza, não pode prescindir da articulação, de mão dupla, entre unidade e o todo" (RESENDE, 2005, p.240).

Mesmo que exista um consenso a respeito do sentido imperativo da participação coletiva na tomada de decisões, conforme indicado por Spósito (2005) "transformado em corrente" como um elo, se este for rompido enfraquece a assunção da perspectiva democrática. A autora explica que, apesar dessa compreensão, a questão da participação envolve maior grau de complexidade do que aparenta. Na maioria vezes, a participação aparece como uma concessão "tutelada por regras burocráticas", ou seja, estabelecendo uma condição de "controle" para que ela exista (SPÓSITO, 2005, p.48).

Diante disso, toda e qualquer instituição educacional que pretenda implantar e desenvolver práticas de natureza participativa na construção do PPP deve ter por base o exercício do diálogo entre todos os envolvidos. Contudo, Veiga (2007) alerta que uma das dificuldades para o desenvolvimento de formas de participação baseadas no diálogo é a existência da cultura autoritária no interior das organizações.

Como já mencionado, somente os professores concursados participaram das discussões a respeito da (re) elaboração do projeto. Nesse sentido, buscamos identificar se, de fato, o PPP apresenta-se como norteador da prática pedagógica. A Professora 1 entende que "em parte, a proposta fica na mesa da sala dos professores a disposição de todos os funcionários e pais, mas dificilmente é manuseada”; a Professora 2 considera que "sim, todo final e início de ano reestruturamos os referenciais curriculares e projetos a serem ministrados durante o ano, no qual cumprimos e norteamos a prática pedagógica da instituição"; e a Professora 3 diz que "em parte, usamos o item que consta o referencial curricular". 
Conforme informado (Professora 1), o projeto (documento) fica a disposição, mas este, raramente, é utilizado, porém, nessa situação, compreendemos que existe um problema de identificação por parte dos professores em relação ao PPP, pois se, de fato, este não foi construído de modo coletivo, dificilmente será reconhecido por outros. Já as Professoras 2 e 3 apreendem o PPP como um documento de consulta curricular (conteúdos a serem seguidos), ou seja, de referência burocrática do que vai ser cobrado por bimestre e não como identidade viva da instituição.

Sobre as ações pedagógicas explicitadas no PPP, indagamos se estas estão de acordo com as desenvolvidas em sala de aula. A Professora 1 explicou que "os professores realizam mensalmente seus planejamentos que são supervisionados pela coordenação pedagógica, mas é preciso muito empenho das pessoas que estão em sala de aula”; a Professora 2 informou que "sim, o referencial curricular e os projetos são a base para os planejamentos mensais e semanais a serem desenvolvidos em sala"; já a Professora 3 entende que acontece "em parte", pois "a prática pedagógica é baseada no referencial curricular".

Silva (2012) reforça ao apontar que somente a perspectiva do projeto que anseia potencializar a multiplicidade de ações da unidade educacional não pode ser concebida como instrumento de controle burocrático do trabalho docente, elaborado para atender as exigências dos órgãos superiores ou ao elenco de conteúdos curriculares. Nessa compreensão, a construção participativa e autônoma docente fica comprometida, tornando o professor incapaz de analisar sua prática pedagógica com seus determinantes, bem como de pensar e planejar ações interventivas que transformem o trabalho educativo e a realidade.

Ao final do questionário, duas professoras optaram por acrescentar algumas falas complementares a coleta de dados, o que pode ser entendido como anseio por parte destas professoras no sentido de vislumbrar mudanças, bem como ser aproveitado na constituição de desafios a serem superados coletivamente. A Professora 1 assinalou que "o PPP deveria ser mais divulgado, tanto dentro da escola como fora dela" e, ainda acrescentou que "quando se faz uma reunião com os pais e toda a comunidade escolar percebemos que eles não conhecem e nem tem interesse em conhecer o documento, isso talvez aconteça pela não participação em sua elaboração"; a Professora 3 desabafou, dizendo que "a forma como o PPP é feito não colabora para sua utilização, na minha opinião desperdiça-se muito tempo discutindo, para depois não usá-lo, fica como algo sem sentido".

Para Spósito (2005), a constituição da participação no interior da unidade educacional exige explicitações de outros pressupostos por parte daqueles que a assumem, como: primeiro, diz respeito ao "caráter público" da atividade educativa, que implica superar ações políticas sob a égide de interesses particulares ou de pequenos grupos, em detrimento de propostas mais amplas; segundo trata do caráter dessa participação, mais do que integração da escola com a comunidade interna e externa, é preciso entender essa presença como mecanismo de representação e participação 
política. Dessa forma, “[...] a gestão tenderá a ser concebida como direitos concretos de cidadania e não como dádiva” (Ibid., p.50).

Assim, apesar de haver participação de algumas professoras na elaboração do PPP, essa participação se dá de forma fragmentada, já que tais professoras dividiram a tarefa de elaboração do PPP, de modo ficou sob incumbência das mesmas discutiram e elaboraram determinados itens do referido projeto.

\section{CONSIDERAÇÕES FINAIS}

Diante de tudo que foi exposto, inferimos algumas considerações sobre o cenário pesquisado, como: a instituição investigada tem dificuldades de direcionamento da construção, elaboração e efetivação do PPP; existem situações que impedem a real efetivação do projeto como mecanismo de promoção da gestão democrática; os níveis de participação e envolvimento dos professores no processo de (re) elaboração e utilização do PPP são limitados; como referência das ações pedagógicas e institucionais serve como direcionamento somente em alguns momentos - consulta ao Referencial Curricular do município.

Contudo, percebemos que existe uma compreensão por parte dos professores em ampliar, mesmo com ressalvas, a participação de outros professores (contratados) nas decisões e discussões a respeito do PPP, o que pode se constituir como positivo, tendo em vista que o projeto também é espaço de emancipação do sujeito reflexivo.

Para Silva (2012), os elementos básicos para a construção de um projeto coletivo são aqueles que conseguimos ver pela frente, a partir das experiências que temos como professores, seja de autores/atores, que em vários momentos confessam suas dificuldades e incertezas na construção dos PPPs de suas escolas.

Abdalla (2012) apoiada em Sacristán (2000) explica que na busca de respostas a essas questões e com base nas necessidades e expectativas dos professores a respeito de sua identidade profissional e da situação problemática que enfrentam no cotidiano escolar, é que poderemos compreender o projeto como um "processo historicamente condicionado, pertencente a uma sociedade, mas não apenas com capacidade de reproduzir, mas também de incidir nessa mesma sociedade" (ABDALLA, 2012 apud SACRISTÁN, 2000, p.160).

Nesse espaço de intervenção renovadora, compete a equipe pedagógica, como um todo e aos professores, em especial, situar continuamente, quais são as suas posições diante das regras institucionais impostas pela sociedade atual e pelo contexto escolar. $\mathrm{E}$, para isso, é preciso pensar em como organizar o melhor trabalho que tenha "em seu bojo, aquela qualidade ausente, colocada como utópica” (ABDALLA, 2012, p.161).

Implica, sobretudo, um trabalho coletivo que busque um debate democrático para que as tomadas de decisão possam ser mais conscientes e críticas (VEIGA; ARAUJO, 
2012). Nessa perspectiva destacamos a importância de: conhecer as necessidades e as expectativas do grupo ao qual pertencem professores, alunos e comunidade escolar; compreender mais a fundo os pontos de vista que recuperem o interesse institucional e social; e ressignificar o trabalho coletivo como um momento valoroso de prática social e educativa e, de organização do trabalho pedagógico como um todo, das intenções do projeto às ações a serem realizadas.

Por fim, almejamos que este estudo apresente-se como fonte relevante para futuras pesquisas da área e que contribua efetivamente para a valorização e reconhecimento do PPP como mecanismo de materialização da participação democrática no âmbito do atendimento a primeira infância.

\section{REFERÊNCIAS}

ABDALLA, M. de F. B. A construção do Projeto Político-Pedagógico e a formação permanente dos professores: possibilidades e desafios. In: VEIGA, I. P. A. (Org.) Quem sabe faz a hora de construir o Projeto Político-Pedagógico. 2. ed. Campinas, SP: Papirus, 2012.

BASTOS, J. B. Gestão democrática da educação: as práticas administrativas compartilhadas. In: BASTOS, J. B. (Org.). Gestão democrática. 4. ed. Rio de Janeiro: DP\&A, 2005.

BRASIL. Constituição. Coleção Legislação Brasileira. Brasília, DF, 05 de out.1988. Lei no 9.394, de 20 de dezembro de 1996. Diário Oficial da União, Poder legislativo, Brasília, DF, 23 de dez. 1996. Brasília, 1996.

Diretrizes Curriculares Nacionais para Educação Infantil. Brasília: MEC/SEB/ DICEI, 2010.

CELANTE, L. G. A construção dos Planos de Desenvolvimento da unidade no projeto pedagógico de duas creches de Jundiaí. 229f. Dissertação (Mestrado em Educação) Faculdade de Educação. Universidade Estadual de Campinas, Campinas, SP, 2005.

ESTEBAN, M. P. S. Pesquisa Qualitativa em Educação: Fundamentos e tradições. Tradução Miguel Cabrera. Porto Alegre: AMGH, 2010.

EVANGELISTA, M. M. T. T. A Construção do Projeto Político-Pedagógico na Escola Municipal de Educação Infantil (Emei) "Florípes Silveira de Souza”. 228f. Dissertação (Mestrado em Educação) - Faculdade de Filosofia e Ciências. Universidade Estadual Paulista Júlio de Mesquita Filho, Marília, SP, 2007.

FERNANDES, M. D. E.; ALVES, A. V. V.; ALVES, A. G. de R. Gestão democrática da educação: por entre concepções e tendências. Dialogia, São Paulo, n. 19, p. 35-45, jan./jun. 2014.

FLICK, U. Uma introdução à pesquisa qualitativa. Porto Alegre: Bookmann, 2004.

FRANCO, M. L. P. B. Análise de Conteúdo. 3. ed. Brasília: Liber Livro Editora, 2008.

GANZELI, P. Administração e gestão. Campinas: UNICAMP, 2005. 
GRACINDO, R. V. Gestão democrática nos sistemas e na escola. Brasília: UNB, 2007.

ITAPORÃ. Lei Orgânica do Município de Itaporã, 1990. Disponível em: <http://www. itapora.ms.gov.br/base/www/itapora.ms.gov.br/media/attachments/122/122/537472b176b9 67d09c1623daa4b4a1b3ada3304d1098f_lei-organica-do-municipio-de-itapora-1990.pdf.>. Acesso em: fev. de 2015.

Projeto Político-Pedagógico do Centro Municipal de Educação Infantil. ItaporãMS: CMEI, 2014.

LIBÂNEO, J. C.; OLIVEIRA, J. F. de; TOSCHI, M. S. Educação escolar: políticas, estrutura e organização. 10. ed. revisão ampliada. São Paulo: Cortez, 2012.

PARO, V. H. Gestão democrática da escola pública. São Paulo: Ática, 2008.

SILVA, E. F. da. A coordenação pedagógica como espaço de organização do trabalho escolar: o que temos e o que queremos. In: VEIGA, I. P. A. (Org.). Quem sabe faz a hora de construir o Projeto Político-Pedagógico. 2. ed. Campinas, SP: Papirus, 2012.

SILVA, A. S. da; OLIVEIRA, M. C. de S; NOGUEIRA, R. M. de S. Professores e crianças como sujeitos na construção da Pedagogia da educação Infantil. In: KASSAR, M. de C. M.; SILVA, F. de C. T. (Orgs.). Educação e Pesquisa no Centro-Oeste: processos de escolarização e práticas educativas. Campo Grande: Editora UFMS, 2012.

SPÓSITO, M. P. Educação, gestão democrática e participação popular. In: BASTOS, J. B. (Org.). Gestão democrática. 4. ed. Rio de Janeiro: DP\&A, 2005.

VEIGA, I. P. A. Projeto político-pedagógico da escola: uma construção coletiva. In: VEIGA, I. P. A. (Org.). Projeto político-pedagógico da escola: uma construção possível. 14 ed. São Paulo: Papirus, 2002.

A. Projeto político-pedagógico: novas trilhas para a escola. In: VEIGA, I. P. A. et al. (Orgs.) As dimensões do Projeto Político-Pedagógico. 5. ed. Campinas, SP: Papirus, 2007.

VEIGA, I. P. A.; ARAUJO, J. C. S. O projeto político-pedagógico: um guia para formação humana. In: VEIGA, I. P. A. (Org.). Quem sabe faz a hora de construir o Projeto PolíticoPedagógico. 2. ed. Campinas, SP: Papirus, 2012. 